\title{
Effect of wear debris on fretting fatigue crack initiation
}

\author{
Shengjie WANG ${ }^{1}$, Tongyan YUE ${ }^{2}$, Dagang WANG ${ }^{3}$, Magd ABDEL WAHAB ${ }^{4,5, *}$ \\ ${ }^{I}$ Soete Laboratory, Department of Electrical Energy, Metals, Mechanical Construction \& Systems, Faculty of Engineering and Architecture, \\ Ghent University, Ghent 9052, Belgium \\ ${ }^{2}$ State Grid Xinyuan Maintenance Branch, Beijing 100000, China \\ ${ }^{3}$ School of Mechatronic Engineering, China University of Mining and Technology, Xuzhou 221116, China \\ ${ }^{4}$ Faculty of Engineering, Van Lang University, Ho Chi Minh City 700000, Vietnam \\ ${ }^{5}$ Soete Laboratory, Ghent University, Ghent 9052, Belgium \\ Received: 19 February 2021 / Revised: 21 April 2021 / Accepted: 19 July 2021 \\ (C) The author(s) 2021.
}

\begin{abstract}
Both wear and fatigue occur in fretting condition, and they interact with one another during the whole process. Fretting fatigue is commonly analysed without considering the effect of wear in partial slip regime, although wear affects the lifetime of crack initiation. This paper investigates, for the first time, the effect of wear debris on fretting fatigue crack initiation. To investigate the effect of debris, first fretting wear characteristics in partial slip regime are analysed for loading conditions. Then, the effect of wear on fretting fatigue crack initiation is investigated using Ruiz parameters and critical plane methods without considering the debris effect. Through the results, we can see that loading conditions affect the wear profiles in different ways. Moreover, wear has a significant effect on the fatigue in partial slip regime without considering debris especially on the crack initiation location. Finally, considering wear debris in the analysis, its effect on critical plane parameters is investigated. It is found that by considering the wear debris effect, the fretting fatigue crack initiation location is shifted towards the trailing edge. The predictions of both crack initiation location and lifetime show a good agreement with the experimental data.
\end{abstract}

Keywords: fretting wear; fretting fatigue; critical plane; Ruiz parameter; debris

\section{Introduction}

Fretting is the phenomenon that happens between two contact parts when there is a relative slip between them and pressure on the contact surface [1-3]. For example, fretting is one critical damage for the connection between blade and disk [4] and railway axle press-fits [5]. Vibration of the contact parts is the main cause for fretting [6,7]. Due to the importance of many influencing parameters, it is not easy to simulate the fretting process [8]. With the increment of relative slip, we can classify fretting in three regimes, namely stick regime, mixed slip regime, and gross sliding regime $[9,10]$. In gross sliding regime, wear is the leading damage, while in stick and mixed slip regimes fatigue plays a key role [11-16]. In mixed slip regime, there is a competence between wear and fatigue. In gross sliding regime, the initiation of micro crack can be suppressed when the wear is significant, which can prolong the fatigue lifetime of the parts. Researchers have made a lot of effort to investigate the crack initiation point and crack propagation path during fretting [17-21]. The main assumption in these analyses is that the change in the contact surface geometry caused by wear can be neglected. Moreover, only one cycle of fretting is used to analyse the stress state and to get the crack initiation lifetime. In the real case, the change in the surface geometry has an effect on the stress state near the contact surface, which is the critical zone for crack initiation. In this way, the analysis of

* Corresponding author: Magd ABDEL WAHAB, E-mail: magd.a.w@vlu.edu.vn; magd.abdelwahab@ugent.be 
one cycle is not enough to consider the stress and strain states during fretting process.

Some researchers have investigated the effect of fretting wear on crack initiation. Madge et al. [22, 23] analysed the critical role of wear on fatigue in fretting for both gross slip regime and partial slip regime. They found that the competence between the wear and fatigue crack initiation on the contact surface was significant and that the wear had alleviated the fatigue damage initiation significantly. Shen et al. [24] considered the wear effect on fretting fatigue crack initiation lifetime based on a damage-coupled elastic-plastic constitutive model, in which the effect of plasticity on damage accumulation and wear characteristics were presented in detail. To increase the accuracy of the prediction, a parameter $D_{\text {fret2 }}$ was combined the Smith Watson Topper (SWT) by Ding et al. [25] to consider the wear effect in fretting. The frictional work threshold $(\tau \sigma)_{\mathrm{th}}$, was used as an indicator to distinguish the zone where wear is dominant. In addition, $\mathrm{O}^{\prime}$ Halloran et al. [26] validated this parameter using a cylinder on flat specimen configuration and found that this method could reduce the computational time significantly, because the calculation of the wear depth on contact surface was not necessary for combined $D_{\text {fret2 } 2 \text { SWT. }}$

Fretting wear affects not only the crack initiation, but also the crack propagation. The effect of wear on crack propagation is also significant, which is caused by the redistribution of the shear stress [27]. The implementation of crack propagation under fretting conditions through the commercial software ABAQUS was first proposed by Giner et al. [28, 29]. Llavori et al. [30] analysed the wear profile effect on crack propagation and found that considering wear could lead to a more accurate crack propagation path and lifetime. Hattori and Watanabe [31] investigated the effect of wear on crack propagation in fretting fatigue specimen based on stress intensity factor by both finite element method (FEM) and experiments. They found that the fatigue strength decreased with the evolution of the wear profiles. For discrete crack that may happen in fretting fatigue, it can be modelled based on the cracking particle method which was proposed and developed by Rabczuk et al. [32-34] for 2D and 3D crack propagation. This phenomenon has not been considered in fretting fatigue yet. Wang et al. [35] analyzed the dynamic wear characteristics of steel wires, commonly used for transmitting electricity, in fretting and the effect of these wear characteristics on crack propagation. It was concluded that the elliptical wear scar and parabolic wear depth were found and fitted well with the prediction equation and the crack initiates from the wear scar. Moreover, the effect of cross angle and friction-increasing grease between steel wires were also analyzed in Refs. [36, 37], respectively.

In this paper, we mainly analyse the effect of wear debris on fretting fatigue crack initiation parameters using Ruiz parameter, Findley parameter (FP) and SWT. The variation of these parameters with cycles is analysed in detail. Moreover, the effect of loading conditions on wear profiles is also analysed. This paper is structured as follows. After the introduction in Section 1, the theoretical background is given in Section 2. Then the experimental set-up is presented in Section 3, after which the numerical model is described in detail in Section 4. After providing results and discussion in Section 5, the conclusion is reported in Section 6.

\section{Theoretical background}

In following subsections, Ruiz parameter, critical plane methods, damage accumulation model, and wear models are described in detail.

\subsection{Ruiz parameter}

Ruiz et al. [38] used two damage parameters to analyse the fretting phenomenon in a dovetail joint at the first instant. The first damage parameter, $F_{1}$ is proportional to the frictional energy per unit area, which is given by Ref. [39]:

$$
F_{1}=\tau \delta
$$

where $\tau$ is the shear stress on the contact surface and $\delta$ is the relative slip between two contact surfaces. This parameter can be used to indicate the extent of the surface material removal, because the frictional energy is proportional to the material removal in the dissipated energy wear model [38]. It should be noted that in fretting, the shear stress is always changing with loading history during one cycle. However, $F_{1}$ is the value at the maximum loading case and in this 
equation, the tensile stress applied on the specimen is not considered.

To consider the tensile stress, the second damage Ruiz parameter $F_{2}$ was proposed as Ref. [38]:

$$
F_{2}=\tau \delta \sigma_{x x}
$$

where $\sigma_{x x}$ is the tensile stress. $F_{2}$ can be used for the maximum wear damage location. However, the maximum wear damage location usually differs from the crack initiation point due to the competence between wear and crack initiation. Through experiments, it was observed that $F_{2}$ could be used for the prediction of the position of crack initiation point.

\subsection{Critical plane methods}

Many multiaxial fatigue criteria have been used for prediction of crack initiation lifetime of fretting fatigue. Critical plane approaches are mostly used due to their applicability and generality [20]. There are three kinds of critical plane methods, namely stress-based, strain-based, and energy-based critical plane method. FP, Fatemi-Socie parameter (FS), and SWT are the corresponding three kinds of critical plane methods, which are used in this paper to predict the crack initiation lifetime of fretting fatigue considering the effect of wear. These three methods are summarised as follows:

FP criterion is firstly proposed by Findley in Ref. [40], which is a typical critical plane method to calculate the direction and position of crack nucleation in early stage [41]. FP is given by Ref. [18]:

$$
\mathrm{FP}=\frac{\Delta \tau_{\max }}{2}+k_{1} \sigma_{n}^{\max }
$$

where $\Delta \tau_{\max }$ and $\sigma_{n}^{\max }$ are the maximum range of shear stress and the maximum normal stress on the critical plane during one fretting cycle, respectively, and $k_{1}$ is determined by the fatigue limit in tension $\sigma_{f-1}$ and torsion $\tau_{f-1}$, when the stress ratio $R$ is equal to $-1 . k_{1}$ is determined from the following equation:

$$
\frac{\sigma_{f-1}}{\tau_{f-1}}=\frac{2}{1+\frac{k_{1}}{\sqrt{1+k_{1}^{2}}}}
$$

To determine the angle of the critical plane, the angle $\theta$, varying from $-90^{\circ}$ to $90^{\circ}$ with the interval been $1^{\circ}$, is used to get the maximum shear stress range on one point as shown in Fig. 1.

The stress and strain on the corresponding critical plane are given as

$$
\begin{aligned}
& \sigma_{x^{\prime}}=\frac{\sigma_{x}+\sigma_{y}}{2}+\frac{\sigma_{x}-\sigma_{y}}{2} \cos 2 \theta+\tau_{x y} \sin 2 \theta \\
& \tau_{x^{\prime} y^{\prime}}=-\frac{\sigma_{x}-\sigma_{y}}{2} \sin 2 \theta+\tau_{x y} \cos 2 \theta \\
& \varepsilon_{x^{\prime}}=\frac{\varepsilon_{x}+\varepsilon_{y}}{2}+\frac{\varepsilon_{x}-\varepsilon_{y}}{2} \cos 2 \theta+\frac{\gamma_{x y}}{2} \sin 2 \theta \\
& \gamma_{x^{\prime} y^{\prime}}=-\frac{\varepsilon_{x}-\varepsilon_{y}}{2} \sin 2 \theta+\frac{\gamma_{x y}}{2} \cos 2 \theta
\end{aligned}
$$

where $\sigma_{x^{\prime}}, \tau_{x^{\prime} y^{\prime}} \varepsilon_{x^{\prime}}$, and $\gamma_{x^{\prime} y^{\prime}}$ are the normal stress, shear stress, normal strain, and shear strain, respectively, on the corresponding critical plane. The transformation and the critical plane selection are also used for the other critical plane parameters.

FP is used to predict the crack initiation lifetime and the equation for lifetime prediction is given by Refs. [42, 43]:

$$
\mathrm{FP}=\tau_{\mathrm{f}}^{\prime}\left(2 N_{i}\right)^{b^{\prime}}
$$

where $\tau_{\mathrm{f}}^{\prime}$ is the coefficient of shear fatigue strength, $N_{\mathrm{i}}$ is the crack initiation lifetime, and $b^{\prime}$ is an exponent of torsion fatigue strength.

Fatemi and Socie [44] proposed a strain-based critical plane method, FS, as shown in Eq. (7). Where $\Delta \gamma_{\max }$ is the maximum shear strain range and $\sigma_{n}^{\max }$ is the corresponding normal stress, $\sigma_{y}$ is the yield stress, and $k_{2}$ is the material constant, which is approximately equal to $\sigma_{y} / \sigma_{\mathrm{f}}^{\prime}$ [45]. The relationship that links FS and crack initiation lifetime is given in Eq. (8) [46], where $\gamma_{\mathrm{f}}^{\prime}$ is the shear fatigue ductility coefficient, $G$ is the shear modulus, $b$ is the fatigue strength exponent in

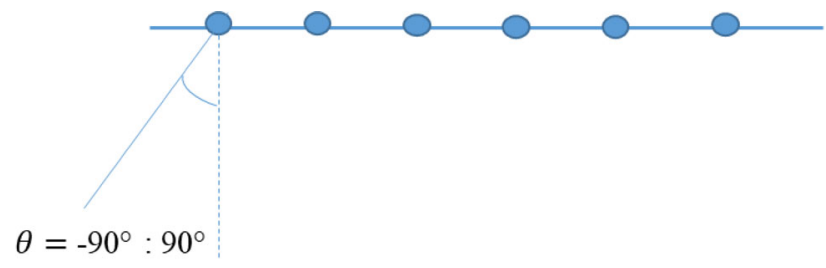

Fig. 1 Sketch of the angle of the critical plane on one point. 
torsion, and $c$ is the fatigue ductility exponent in tension.

$$
\begin{gathered}
\mathrm{FS}=\frac{\Delta \gamma_{\max }}{2}\left(1+k_{2} \frac{\sigma_{n}^{\max }}{\sigma_{y}}\right) \\
\mathrm{FS}=\frac{\tau_{\mathrm{f}}^{\prime}}{G}\left(2 N_{i}\right)^{b^{\prime}}+\gamma_{\mathrm{f}}^{\prime}\left(2 N_{i}\right)^{c^{\prime}}
\end{gathered}
$$

Another critical plane method is SWT, which is an energy-based method, and is also applied in this investigation. SWT was used as a criterion for fretting fatigue by Szolwinski and Farris and is given by Ref. [47]:

$$
\mathrm{SWT}=\sigma_{n}^{\max } \frac{\Delta \varepsilon_{n}}{2}
$$

where $\sigma_{n}^{\max }$ is the maximum normal stress, while $\Delta \varepsilon_{n}$ is the corresponding strain amplitude. The equation that connects SWT and crack initiation lifetime, $N_{\mathrm{i}}$ is given by

$$
\mathrm{SWT}=\frac{\sigma_{\mathrm{f}}^{\prime 2}}{E}\left(2 N_{i}\right)^{2 b}+\sigma_{\mathrm{f}}^{\prime} \varepsilon_{\mathrm{f}}^{\prime}\left(2 N_{i}\right)^{b+c}
$$

where $\sigma_{\mathrm{f}}^{\prime}$ is the fatigue strength coefficient, $\varepsilon_{\mathrm{f}}^{\prime}$ is the fatigue ductility coefficient, $E$ is the Young's modulus, $b$ is the fatigue strength exponent, and $c$ is the fatigue ductility exponent. $b$ and $c$ are the same as $b$ and $c$, respectively.

\subsection{Wear model}

Two wear quantification models are commonly used for fretting wear analysis, namely Archard's model and dissipated energy model $[13,15,48]$. The basic theory for the wear model is Archard's equation [49]:

$$
V=k_{\mathrm{A}} S P
$$

where $k_{\mathrm{A}}$ is Archard wear coefficient, $S$ is the total sliding distance, $P$ is the normal load, and $V$ is the wear volume. $S$ can be obtained by multiplying 4 times the relative slip amplitude $\delta$ (half stroke) and the number of cycles, $N$. Then, Eq. (10) can be written as

$$
k_{\mathrm{A}}=\frac{V}{4 \times \delta \times N \times P}
$$

Dissipated energy model shows its advantage when the coefficient of friction (COF) is variable. The equation of dissipated energy is shown in Eq. (12). The dissipated model and the Archard's equation are equivalent when the coefficient of friction is a constant. The relation between dissipated energy wear coefficient and Archard's wear coefficient is: $k_{\mathrm{A}}=\mu K_{\mathrm{E}}$.

$$
\Delta h_{\mathrm{i}}=K_{\mathrm{E}} \int_{0}^{T} q_{i}(x) \mathrm{d} s_{i}(x)
$$

where $K_{\mathrm{E}}$ is the dissipated energy wear coefficient, $\Delta h_{i}$ is the local wear depth, $T$ is one cycle period and $s_{i}(x)$ and $q_{i}(x)$ are incremental relative slip and shear stress on the surface position $x$.

In this paper, the dissipated energy model is used for the calculation of the local wear depth in FE model.

\subsection{Damage evolution model}

Crack initiation of the material under fretting condition is not a sudden phenomenon. Damage is accumulated cycle by cycle until a crack is initiated. In addition, when considering wear, the contact geometry is always changing during fretting process. FP parameter and predicted life vary with cycles. To consider this, Miner's rule is employed, as proposed in Ref. [50]:

$$
V_{\mathrm{D}}=\sum_{j=1}^{\frac{N_{\mathrm{t}}}{\Delta N}} \frac{\Delta N}{N_{i, j}}
$$

where $V_{\mathrm{D}}$ is the accumulated value of damage, $\Delta N$ is the jumped cycles to optimise the simulation time, $N_{\mathrm{t}}$ is the gross cycles number and $N_{i, j}$ is the predicted nucleation lifetime for $j^{\text {th }}$ jump cycle. This damage model is widely used to calculate the cycle- by-cycle damage accumulation $[22,30,51]$.

\section{Experimental set-up}

The schematic of the experimental set-up is shown in Fig. 2 [41]. The normal load $(P)$ is applied on the top of cylinders from both sides, after which the tangential load $(Q)$ is applied on the right-hand side of the cylinders. Moreover, the cyclic axial stress, $\sigma_{\mathrm{A}}$ is applied on the right-hand side of the specimen. The tangential stress ratio and the axial stress ratio are all equal to 1. Experimental data for fretting fatigue test is shown in Table 1 [41]. 


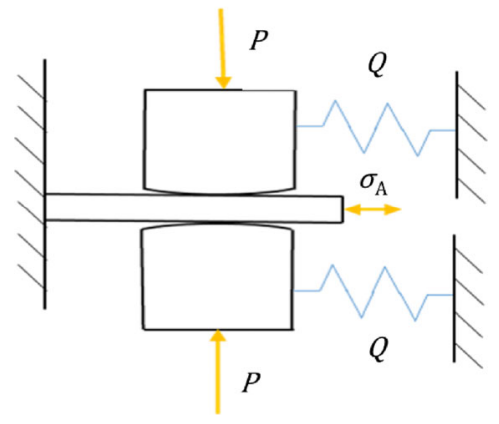

Fig. 2 Schematic of the experimental set-up.

Table 1 Experimental data for fretting fatigue test.

\begin{tabular}{ccccc}
\hline No. & $P(\mathrm{~N})$ & $Q(\mathrm{~N})$ & $\sigma_{\mathrm{A}}(\mathrm{MPa})$ & $N_{\text {exp }}^{i}$ cycles \\
\hline 1 & 7,085 & $1,487.8$ & 85.2 & 684,658 \\
2 & 6,176 & $1,667.5$ & 84.7 & 555,830 \\
3 & 6,460 & $2,196.4$ & 106.4 & 195,200 \\
4 & 5,319 & $1,914.8$ & 97.4 & 418,911 \\
5 & 5,310 & $2,017.8$ & 85.8 & 519,963 \\
6 & 6,268 & $1,692.4$ & 100 & 312,062 \\
\hline
\end{tabular}

The material of both specimen and cylinders is Aluminum 2024-T351. The Young's modulus $(E)$ and Poisson's ratio $(v)$ are $74.1 \mathrm{GPa}$ and 0.33 , respectively. The shear modulus $G$ is $28 \mathrm{GPa}$, and other material parameters are summarised in Table 2, where $\sigma_{u}$ is the ultimate tensile strength $[52,53]$.

The minimum dissipated energy wear coefficient, $K_{\mathrm{E}}$ in sliding condition for pin-on-disc configuration is $3.7 \times 10^{-8} \mathrm{MPa}^{-1}$ [54]. In partial slip regime, the wear coefficient should be lower. This is because in the contact centre there is a stick zone that supports the partial normal load, where there is no slip to cause wear on the contact surface. Considering this situation, $1.4 \times 10^{-8} \mathrm{MPa}^{-1}$ is used for the wear coefficient for 2024-T351 in partial slip regime.

\section{Numerical model}

\subsection{FE model}

The non-linear finite element (FE) model, which is shown in Fig. 3, is constructed in the commercial software ABAQUS using python scripts. 4-node bilinear plane strain quadrilateral (CPE4) element is used for the whole model. The radius of the cylinder is $178 \mathrm{~mm}$. The heights of cylinder and specimen are 25 and $6.35 \mathrm{~mm}$, respectively, and the lengths of cylinder and specimen are 25 and $40 \mathrm{~mm}$, respectively. The thickness is $12.7 \mathrm{~mm}$ for both cylinder and flat. To consider both efficiency and accuracy of the model, the partition is used for both parts. The mesh in both contact zones is magnified in Fig. 3, and the element size on the contact surface is $10 \mu \mathrm{m}$. In our previous work in Ref. [55], we analysed the effect of the mesh size for the contact surface on the convergence of the shear stress. The corresponding method was also applied in this paper to investigate the feasibility of the discretization of FE model and found that the stress converged when the mesh size for the contact surface is $10 \mu \mathrm{m}$. Multi point constraint (MPC) is applied on the top of the cylinder. The flat is set as the slave surface, while the cylinder is set as the master surface. Finite sliding formulation and surface to surface discretization method are used for the contact surfaces. Moreover, the adjustment algorithm is used for the slave surface. To make the simulation more efficient, jump cycles, $\Delta N=5,000$, is used in the USER SUBROUTINE UMESHMOTION. When one cycle is simulated in FE model, the local wear depth is obtained by multiplying $\Delta N$. The loading condition history used in FE model is shown in Fig. 4. At the end of the first cycle, the model is submitted for the analysis. The second model

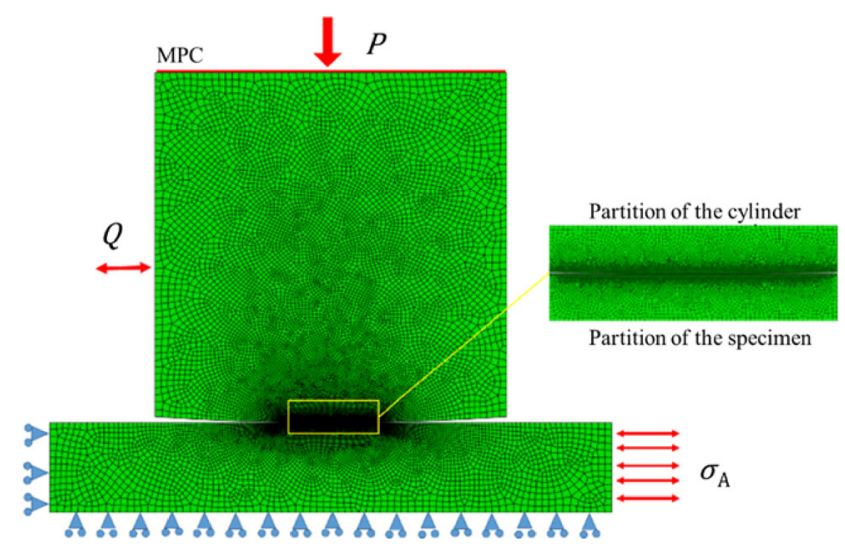

Fig. 3 FE model 1 for the fretting fatigue experiment.

Table 2 Constant of material properties.

\begin{tabular}{cccccccccc}
\hline$\sigma_{\mathrm{f}}^{\prime}(\mathrm{MPa})$ & $\varepsilon_{\mathrm{f}}^{\prime}$ & $b$ & $c$ & $\sigma_{\mathrm{f}-1}(\mathrm{MPa})$ & $\tau_{\mathrm{f}-1}(\mathrm{MPa})$ & $\sigma_{u}(\mathrm{MPa})$ & $\sigma_{y}(\mathrm{MPa})$ & $\tau_{\mathrm{f}}^{\prime}(\mathrm{MPa})$ & $\gamma_{\mathrm{f}}^{\prime}$ \\
\hline 741 & 0.166 & -0.078 & -0.538 & 140 & 80.8 & 425 & 310 & 412.2 & 0.287 \\
\hline
\end{tabular}




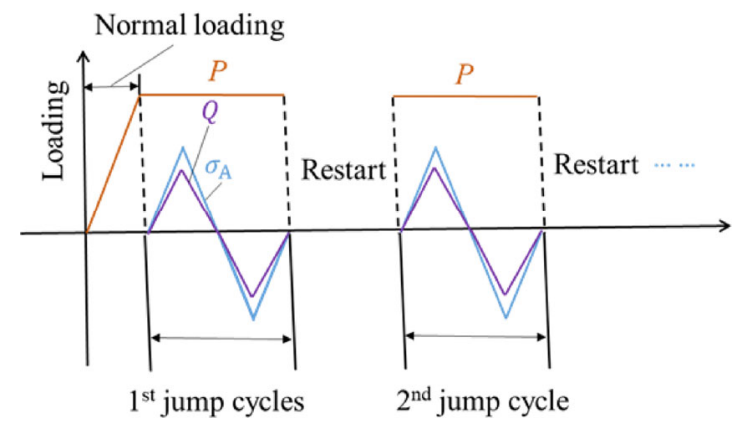

Fig. 4 Loading history for the fretting fatigue experiment.

is established at the end of the first cycle by restating the python code, and then it is submitted for the analysis after applying the oscillatory tangential and axial loads. For the following cycles, the process of the loading is the same.

\subsection{Verification and numerical implementation}

\subsubsection{Verification by contact mechanics}

Based on contact mechanics, the contact pressure can be obtained by Ref. [56]:

$$
p(x)=p_{\max } \sqrt{1-\left(\frac{x}{a}\right)^{2}}, \text { where } p_{\max }=\left(\frac{P E^{*}}{2 \pi L R^{*}}\right)^{\frac{1}{2}}
$$

where $P$ is the normal load, $L$ is the thickness of the specimen along $z$ axis $(L=10 \mathrm{~mm}), R^{*}$ and $E^{*}$ are the equivalent radius and Young's modulus, respectively, and $p_{\max }$ is the maximum contact pressure. $a$ is half contact width, which is given by

$$
a=2 \sqrt{\frac{P R^{*}}{\pi E^{*} L}}
$$

$R^{*}$ and $E^{*}$ can be obtained as

$$
\begin{gathered}
\frac{1}{R^{*}}=\frac{1}{R_{1}}+\frac{1}{R_{2}} \\
\frac{1}{E^{*}}=\frac{1-v_{1}^{2}}{2 E_{1}}+\frac{1-v_{2}^{2}}{2 E_{2}}
\end{gathered}
$$

where $R_{1}$ and $R_{2}$ are the radii, $E_{1}$ and $E_{2}$ are Young's modulus, and $v_{1}$ and $v_{2}$ are the Poisson ratio of the flat and cylinder, respectively.

Moreover, shear distribution in partial slip regime is used to verify the FE model, which is given by Ref. [1]:

$$
\begin{cases}q(x)=-\mu p_{\max } \sqrt{1-\left(\frac{x}{a}\right)^{2}}, & |x+e|>c \\ q(x)=-\mu p_{\max } \sqrt{1-\left(\frac{x}{a}\right)^{2}}+\mu p_{\max } \frac{\mathrm{c}}{a} \sqrt{1-\left(\frac{x+e}{c}\right)^{2}}, & |x+e|<c\end{cases}
$$

where $q(x)$ is the shear stress along the contact width, $\mu$ is $\mathrm{CoF}$, and $c$ is the half stick width. $c$ and the offset, which is influenced by axial stress $\sigma_{\mathrm{A}}$, can be obtained by Eq. (20) [1]. The verification of the FE model by the analytical solution is shown in Fig. 5, from which we can see that the shear stress from FE model shows a good agreement with the analytical solution.

$$
\begin{gathered}
c=a \sqrt{1-\left|\frac{Q}{\mu P}\right|} \\
e=\frac{\sigma_{\mathrm{A}} a}{4 \mu p_{\max }}
\end{gathered}
$$

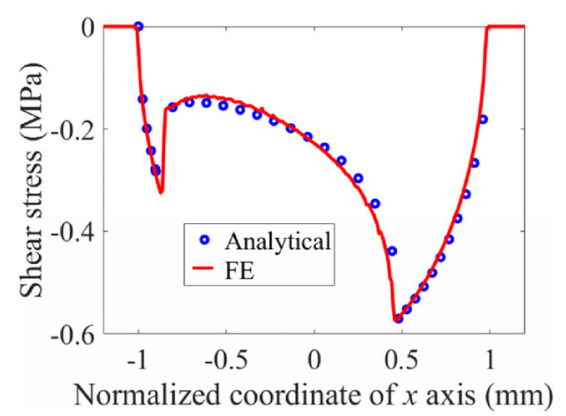

Fig. 5 Verification of the FE model by the analytical solution.

\subsubsection{Models with different boundary conditions}

In some experiments, two parameters are used for the tangential loading, namely tangential load and tangential displacement. In Ref. [39], the effect of boundary conditions is analyzed without considering the effect of wear. It was found that the effect of boundary conditions on the stresses was not significant. In this paper, the effect of the boundary conditions on stresses is analyzed. Based on Experiment 3, the corresponding displacement on the left-hand side of the cylinder can be obtained in model 1 without wear effect. Then, the corresponding oscillatory displacement is applied to the left-hand side of the cylinder in model 2 with wear effect as is shown in Fig. 6. And then, the stresses and wear profile in model 2 are compared with that in model 1 with wear effect. 


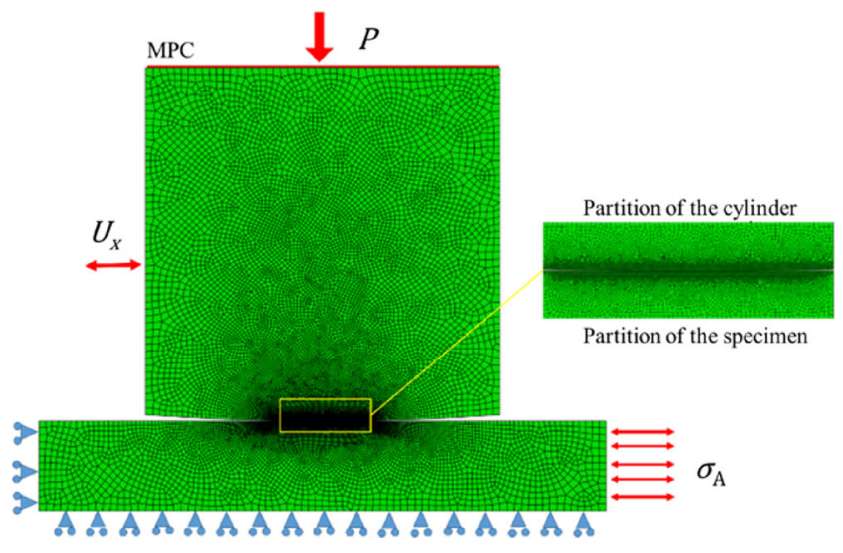

Fig. 6 FE model 2 for the fretting fatigue experiment.

\subsubsection{Loading cases for wear profile analysis}

Because the change of geometry is the key effect on the variation of stresses and damage parameters, it is very important to analyse the details of the wear characteristics, and relate the wear characteristics to stresses, and damage parameters. Based on the loading conditions of Experiment 3, the effect of the normal load, tangential load, axial load, and non-proportional loading is analysed. Loading cases that are used to analyse the loading condition effect on the wear characteristics are listed in Table 3. Experiments 1, 2, and 3 are used to consider the effect of normal load, experiments 4,2 , and 5 are used to analyse the effect of the tangential load, and experiments 6, 2, and 7 are used to analyse the effect of axial load.

Table 3 The loading cases to analyze the effect of loading conditions on wear characteristics.

\begin{tabular}{cccc}
\hline No. & $P(\mathrm{~N})$ & $Q(\mathrm{~N})$ & $\sigma_{\mathrm{A}}(\mathrm{MPa})$ \\
\hline 1 & 4,460 & $2,196.4$ & 106.4 \\
2 & 6,460 & $2,196.4$ & 106.4 \\
3 & 8,460 & $2,196.4$ & 106.4 \\
4 & 6,460 & $1,196.4$ & 106.4 \\
5 & 6,460 & $3,196.4$ & 106.4 \\
6 & 6,460 & $2,196.4$ & 66.4 \\
7 & 6,460 & $2,196.4$ & 146.4 \\
\hline
\end{tabular}

\subsubsection{Crack initiation location and lifetime prediction}

As shown in Fig. 7, the wear profile is updated after each increment and the critical plane parameters are obtained after each cycle. Thereafter, the crack initiation lifetime is calculated, and the damage accumulation parameter is derived from Miner's rule. The cycle stops when the accumulated damage parameter on a contact node is greater than 1 . The critical plane parameters in some cycles are compared and the maximum values of these parameters are considered as the crack initiation point in the corresponding cycle. Then, the crack initiation location in certain cycle is compared using the three critical plane methods. In critical plane methods, the critical plane angle is assumed to be the direction of the crack initiation. By considering to the effect of wear, the Ruiz 2 parameter is also used for the comparison of the crack initiation location with the critical plane methods. Though, Ruiz 1 parameter cannot be used to determine the crack initiation location, because it is a kind of parameter that is proportional to the wear volume. Experiment 1 is used as an example to analyze the evolution of these parameters.

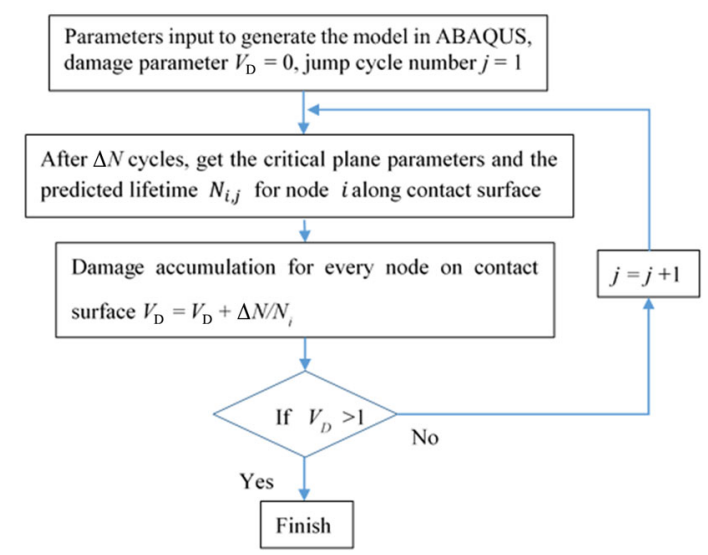

Fig. 7 Flowchart for the implementation of the prediction of crack initiation lifetime.

\subsubsection{Fretting fatigue model with debris layer}

In the experiments, the wear debris lies near the trailing contact edge as shown in Fig. 8 [41]. To model the effect of the debris in the fretting fatigue FE model, the debris layer model concept is considered [15]. The schematic of the debris layer in fretting fatigue model is shown in Fig. 9(b). From the figure, we can see that in the stick zone there is no wear, whereas in partial slip zone wear happens at both sides. This is because not all the wear debris can be ejected from the partial slip zone. $\Delta h$ is the distance from the original surface to the debris layer. Because the wear profile progresses with cycles, the variation of $\Delta h$ should be further validated by experimental data. In the initial 


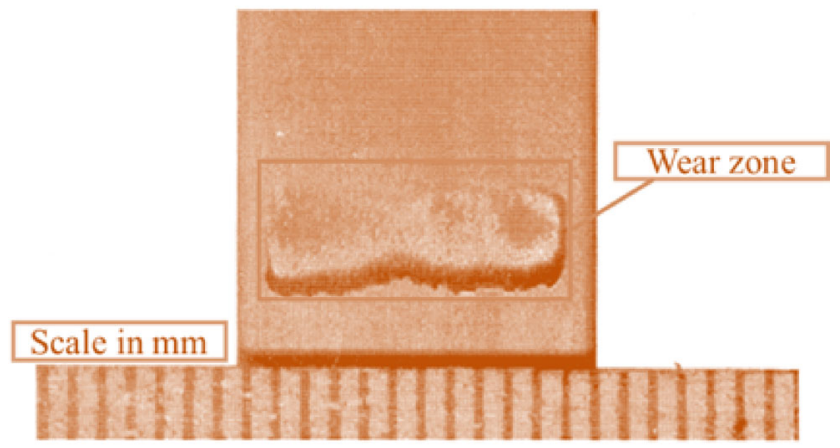

Fig. 8 Experimental wear profile near the trailing edge.

period, the debris effect can be neglected due to the very low wear depth and wear width. After certain cycles, the effect of the debris cannot be ignored anymore. In this paper, we analyse the effect of the debris layer after 100,000 cycles based on Experiment 1 as is shown in Fig. 9(a).

After 100,000 cycles and releasing the normal load, the debris is introduced as shown in Fig. 9(b). Moreover, the wear on the left-hand side can be ignored compared with the wear volume on the right-hand side. If the wear volume is higher in the left-hand side, the debris should also be considered there. There are three contacts in the FE model. The first one is the contact between the bottom of the cylindrical pad and the upside of the debris. The second one is the contact between the bottom of the cylindrical pad and the upside of the flat specimen, and the third one is the bottom of the debris layer and the top of the flat specimen. The bottom of the cylinder is always set as master surface, while the top of the flat specimen is always set as slave surface, as shown in Fig. 10. The coefficient of friction is set as 0.65 for the contact between cylinder and the debris, and between cylinder and flat specimen [41]. For the contact between debris and specimen the coefficient of friction is set as 1.0 which is the same as in Ref. [15]. Due to the lower amount of wear volume in the first 100,000 cycles, the debris is introduced and generated in the model after 100,000 cycles. A schematic for the introduction of the debris to the model is shown in Fig. 11. The releasing step is applied at the end of the $100,000^{\text {th }}$ cycle by restarting through python code. At the end of the releasing step, the normal loading, the oscillatory tangential and axial loads are applied consequently after restarting and introducing the debris to the model.

The material properties of the debris layer are the same as those for the oxide of aluminum. The elastic modulus is $300 \mathrm{GPa}$ and the Poisson's ratio is 0.21 [57].

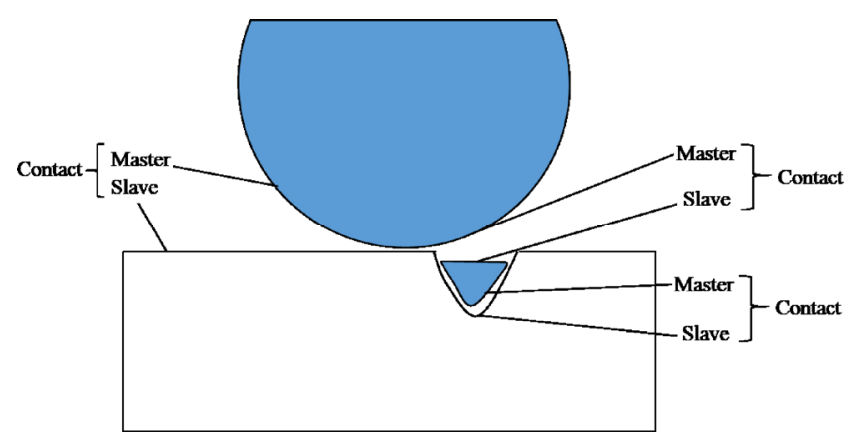

Fig. 10 Schematic of the contact in FE model.

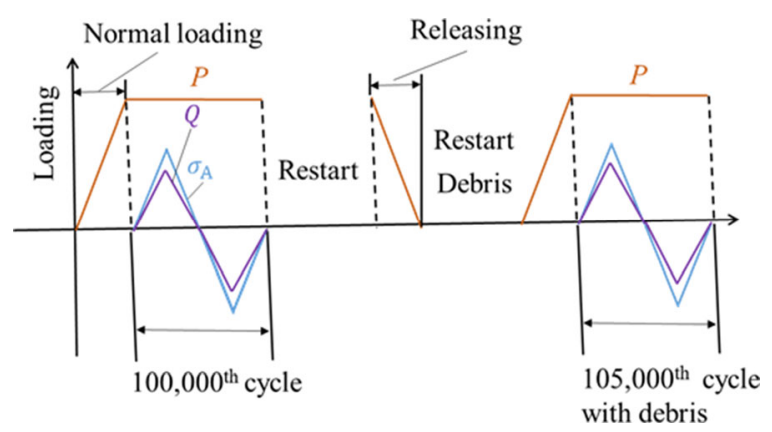

Fig. 11 Schematic of the introduction of the debris to model.

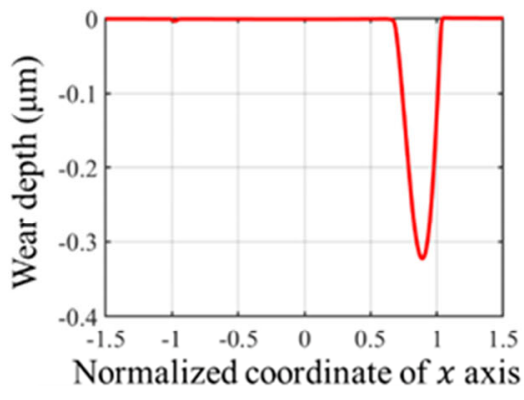

(a)

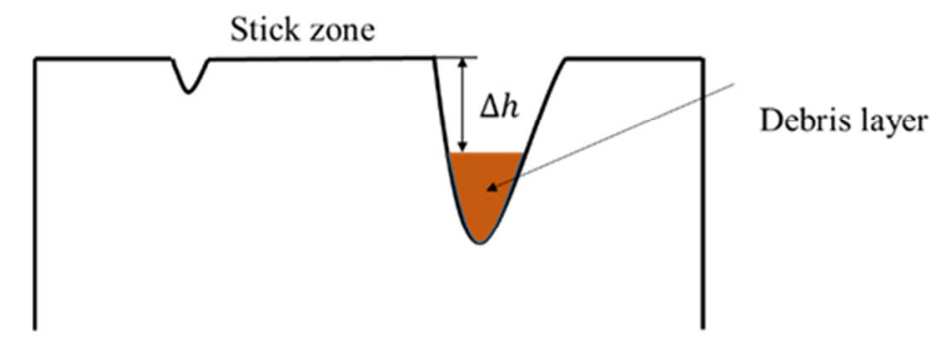

(b)

Fig. 9 Wear profiles: (a) wear profile after 100,000 cycle for Experiment 1, and (b) schematic of the debris layer in fretting fatigue model. 


\section{Results and discussion}

\subsection{Effect of boundary conditions}

Using different boundary conditions, the wear profile changes after 80,000 cycles as shown in Fig. 12(a). The wear depth in the right-hand slip zone is almost the same, while in the left-hand slip zone, the wear depth of model 2 tends to be greater than that of model 1 . Moreover, in the stick zone, there is no slip in model 1, while in model 2, the wear is significant in the initial stick zone. By comparing the shear stress in Fig. 12(b), we can see that in model 2, the shear stress is higher than that in model 1, which means that the boundary conditions influence the shear stress distribution when considering the wear in fretting fatigue. Therefore, higher shear stress in model 2 can lead to more wear in fretting. Maximum shear stresses are found near the boundary of slip and stick zone in both models.

The applied tangential force can lead to a tangential displacement in fretting fatigue physically, and the applied tangential displacement can also lead to a tangential force for the contact parts. When there is no wear, the applied tangential displacement can lead to the corresponding tangential force in fretting fatigue. The profile of the shear stress obtained by applying tangential force is the same as that obtained by applying corresponding tangential displacement when the wear is not considered. This phenomenon is verified in Ref. [58]. When considering wear in fretting fatigue, the tangential force will lead to a different tangential displacement compared with that without considering wear. This is caused by the wear profile. In the experiments, there are also two kinds of tangential loads, tangential force, and tangential displacement. The

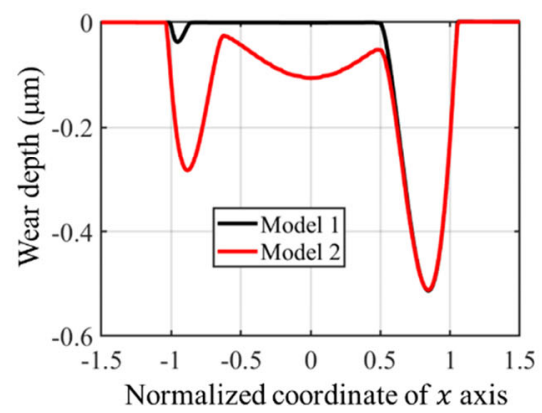

(a) same tangential force could cause different tangential displacement in fretting process. There are lot of experimental fretting loops that shows the history of the tangential force and displacement, which is also not a constant relationship all the time [59]. Therefore, if you applied the tangential displacement obtained in tangential force model without considering wear to the FE model considering wear, the corresponding tangential force for the contact parts will differ from that without considering wear. This caused the difference of the profile of the shear stress and wear for model 1 and model 2. The reason for the wear in stick zone for constant tangential displacement model when considering the wear is that the elastic deformation can no longer accommodate the relative displacement due to the applied constant tangential displacement. This is the effect of the boundary condition on the wear profile when considering wear.

\subsection{Effect of loading cases on wear profiles}

From Fig. 13(a), we can see that the normal load can broaden the contact zone and higher normal load can increase the wear width. Because with higher normal load, the contact width is greater, which broadens the wear profile. Moreover, lower wear depth is found with higher normal load, which is caused by the lower slip amplitude. This is because for the same tangential load there is a small slip zone under higher normal load. Figure 13(b) shows that the higher tangential load can cause greater wear depth due to higher slip amplitude. Because high tangential load can cause higher shear stress on the contact surface, which can cause more wear volume in dissipated energy wear model. Moreover, the location of the maximum wear

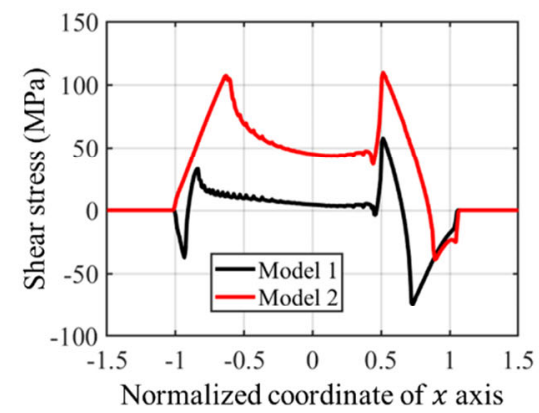

(b)

Fig. 12 Effect of boundary conditions on the wear profile and shear stress: (a) wear profiles after 80,000 cycles and releasing step, and (b) shear stress at the end of $80,000^{\text {th }}$ cycle. 

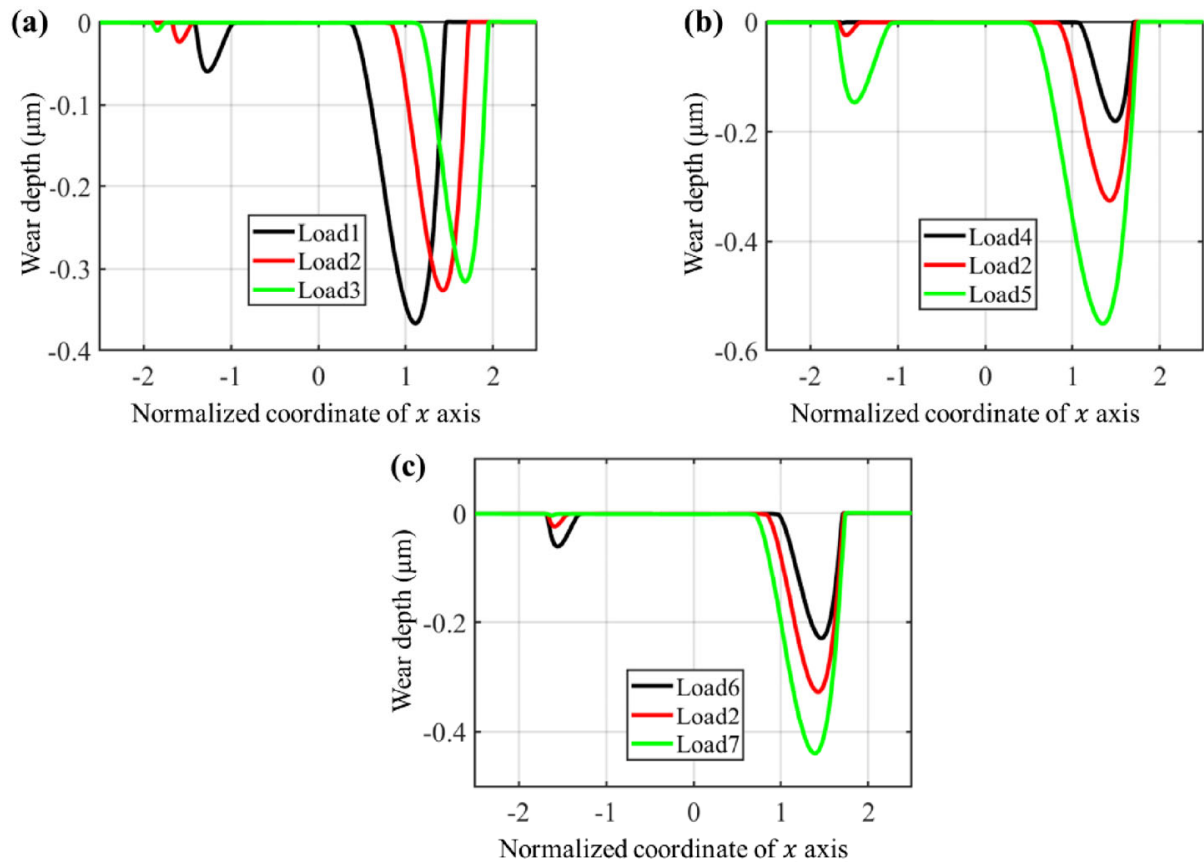

Fig. 13 Effect of loading cases on wear profiles: (a) effect of normal load, (b) effect of tangential load, and (c) effect of axial load.

depth is the same for all three loading cases for both left-hand and right-hand sides. In Fig. 13(c), we can see that the higher axial load can cause greater maximum wear depth on the right-handed side, and lower maximum wear depth on the left-hand side. It means that axial load can affect the relative displacement on both sides, which causes a greater slip amplitude on the right-hand side, and lower slip amplitude on the left-hand side. Because the normal load is the same, the position of the maximum wear depth is the same with different axial and tangential loads.

\subsection{Effect of wear on fatigue initiation position without considering the debris effect}

Figure 14(a) shows that the maximum value of the frictional energy per unit area, $F_{1}$ moves from the trailing edge (right-hand side edge of the contact) to the boundary of the stick-slip zone and decreases with cycles. Near the trailing edge, there is another lower peak that is caused by the negative shear stress near the contact as shown in Fig. 12(b). From Fig. 14(a), we can conclude that the wear zone moves from the trailing edge to the boundary of the stick and slip zone. Near the leading edge, there is a dramatic increase in the value of $F_{1}$ due to the dramatical increment of the shear stress. The trend of $F_{2}$ near the trailing edge in Fig. 14(b) is the same as that in Fig. 14(a), however, $F_{2}$ is very low near the leading edge due to the lower tangential stress.

Variation of critical plane parameters with cycles for

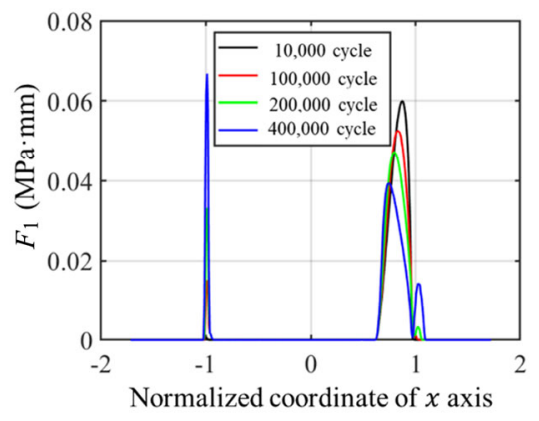

(a)

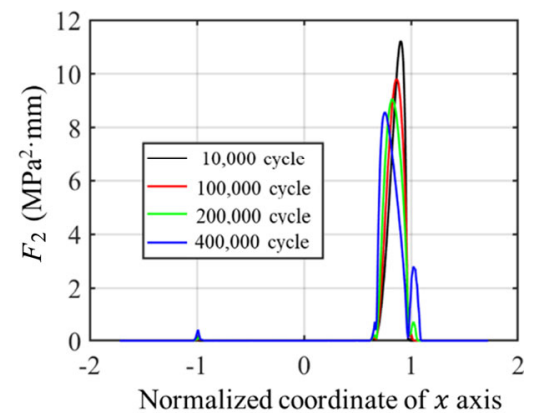

(b)

Fig. 14 Variation of Ruiz parameters with cycles for Experiment 1 when $\sigma_{\mathrm{A}}$ reaches the maximum value. 
Experiment 1 is shown in Fig. 15. From the figure, it can be concluded that the maximum values of FP, FS, and SWT tend to move from the trailing edge to the boundary of the stick-slip zone. The variation tendency

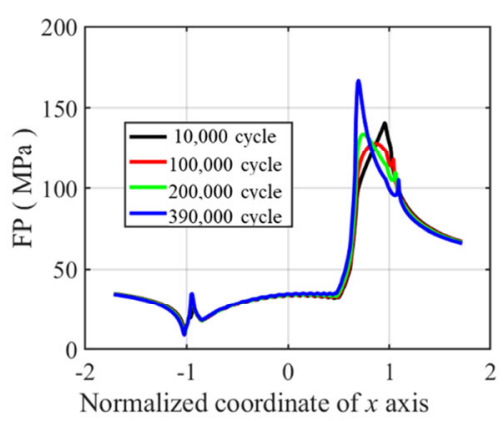

(a) of these three parameters is similar to each other. The crack initiation position predicted by critical plane damage accumulation parameters is shown in Fig. 16. The point of maximum damage accumulation parameter

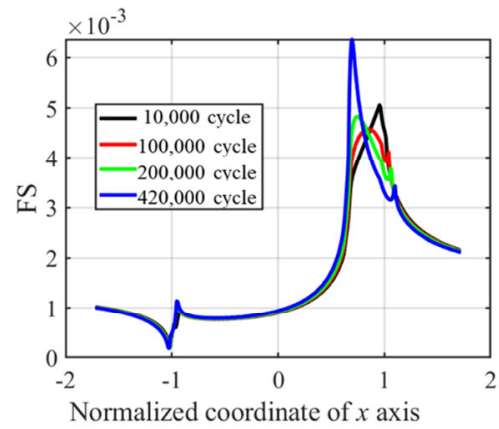

(b)

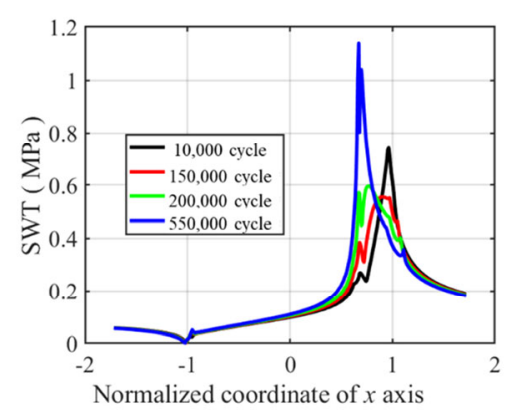

(c)

Fig. 15 Variation of critical plane parameters with cycles for Experiment 1.

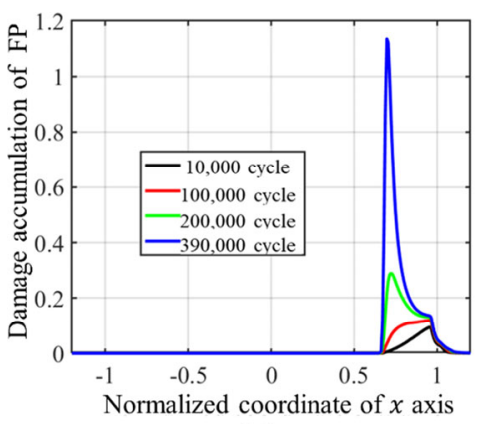

(a)

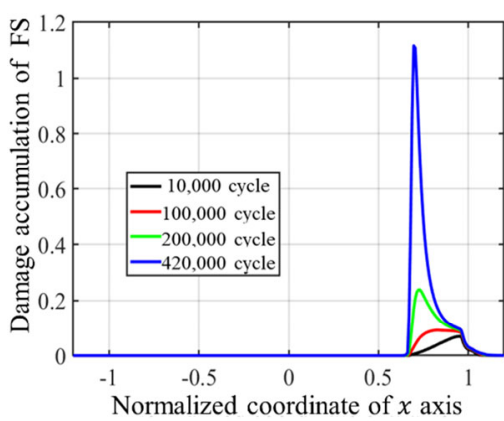

(b)

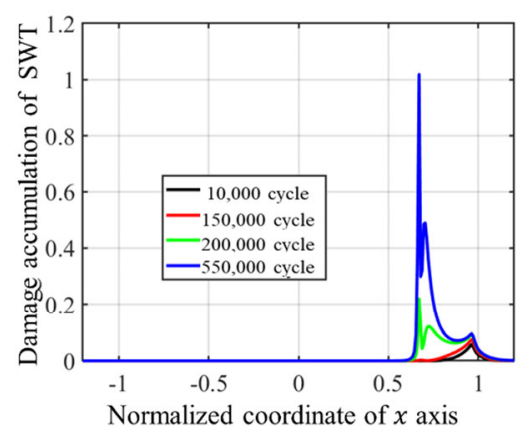

(c)

Fig. 16 Variation of damage accumulation value with cycles for Experiment 1. 
varies from trailing edge to boundary of stick-slip zone due to wear in partial slip zone. This is because the stress concentration can happen at the edge of the stick-slip zone after the material removal in the slip zone. When the maximum damage accumulation parameter reaches to 1 , the predicted crack occurs at the corresponding location. The dramatic increase of the damage accumulation happens near the boundary of the stick-slip zone.

\subsection{Lifetime prediction of crack initiation con- sidering wear effect}

Figure 17 shows that all the predicted lifetime lies in

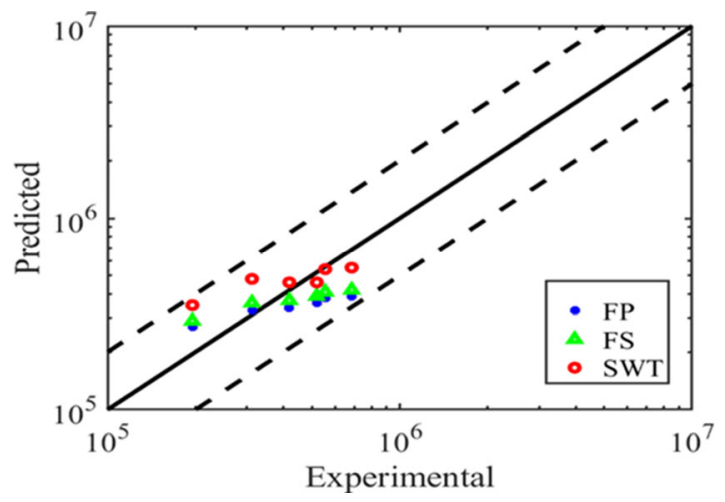

Fig. 17 Crack initiation lifetime predicted by FP, FS, and SWT without considering debris. $\pm 2 N_{i}$ error band. When the experimental lifetime is lower, then the predicted lifetime by all three critical plane methods tends to be higher than the experimental one. When the experimental lifetime is higher, then the predicted lifetime tends to be lower than the experimental one. This phenomenon is caused by the dramatic increase of the critical plane parameters with the evolution of the profiles as shown in Fig. 15.

\subsection{Effect of debris layer on crack initiation parameters}

In the experiments, the crack initiation tends to be near the trailing edge under the debris layer, whereas in the FE model the crack initiation position tends to be near the boundary of stick-slip zone and far away from the contact edge [41]. Therefore, the crack initiation position is analyzed considering the effect of the debris based on Fig. 9. The critical plane parameters considering the debris effect after 100,000 cycles are shown in Fig. 18. The values of 1.5, 2.0, and 2.5 are used for $\Delta h$ as shown in Fig. 9 and the unit is $0.1 \mu \mathrm{m}$. In the model without considering the debris effect, the maximum value locates near the boundary of stick and slip zone, while in the model considering the debris effect the maximum value locates near the trailing edge. After considering the debris layer in the

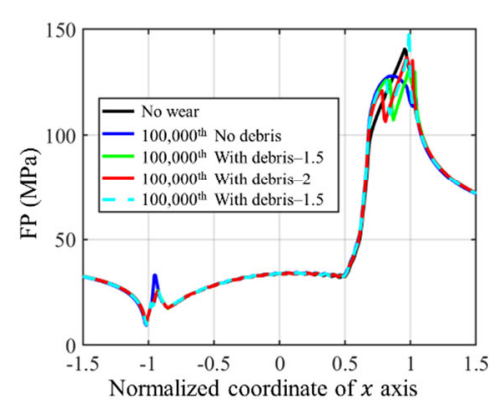

(a)

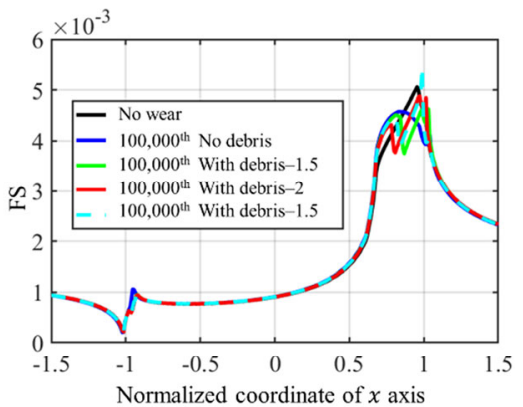

(b)

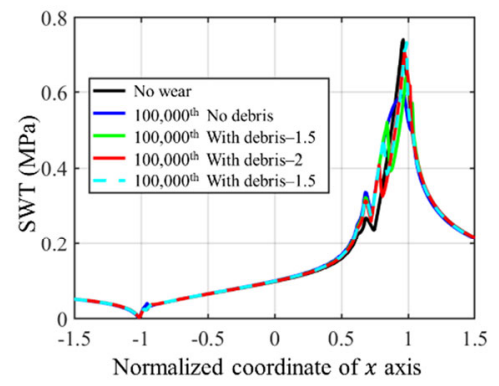

(c)

Fig. 18 Critical plane parameters considering the debris effect after 100,000 cycles for Experiment 1. 
model, the stress concentration on the edge of the slip zone is not that significant anymore compared with that without considering the debris layer. The parameters considering the debris tend to have the same trend as those without wear. Moreover, the depth to the surface of the debris $\Delta h$ also affects the profiles of the parameters on the contact surface. For $\Delta h=0.25 \mu \mathrm{m}$, the maximum values of FP and FS approximate to peak values of the corresponding parameter for the model without debris. This means that $\Delta h$ also plays an important role in the whole process, i.e. the ejection and generation rates also affect the lifetime of the crack initiation. For SWT, the maximum value tends to be the same as that in the model without wear when $\Delta h$ is equal to 0.25 and $0.2 \mu \mathrm{m}$.

The variation of the damage accumulation value for the three critical plane parameters is shown in Fig. 19, when $\Delta h$ is $0.15 \mu \mathrm{m}$. It can be concluded that by considering the effect of wear debris, the crack initiation position moves from the boundary of the stick-slip regime to the trailing edge. Moreover, for the damage accumulation value of FP and FS another peak value appears near the boundary of stick-slip regime. This peak is lower than that near the trailing edge. For SWT, only one peak appears near the trailing edge.

Crack initiation lifetime predicted by FP, FS, and SWT for Exp. 1 considering wear debris when $\Delta h$ is $0.15 \mu \mathrm{m}$ is shown in Fig. 20. We can see that predicted lives using FP, and FS are within $\pm 2 N_{i}$, while most of the predicted lives using SWT are located within $\pm 2 N_{i}$, except 1 point, which is higher that $2 N_{i}$. Moreover, the predicted lives using SWT tend to be higher than those using FP.

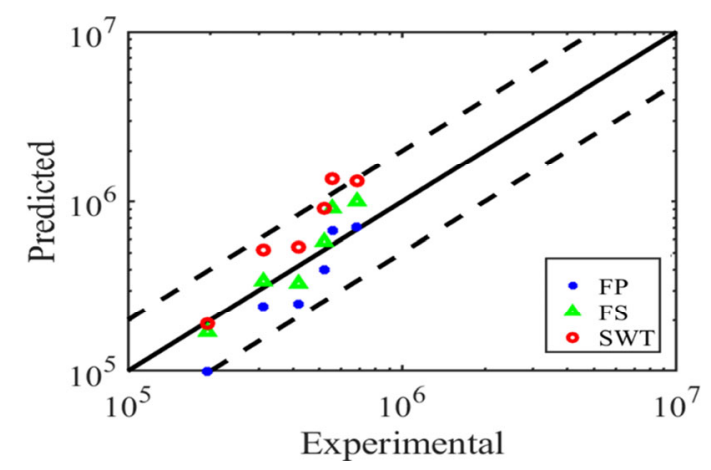

Fig. 20 Crack initiation lifetime predicted by FP, FS, and SWT considering debris when $\Delta h$ is $0.15 \mu \mathrm{m}$.

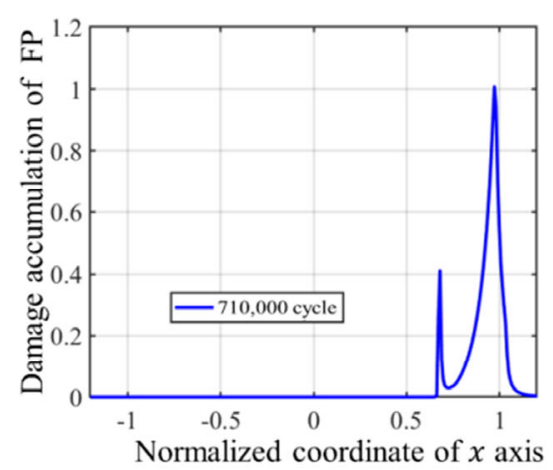

(a)

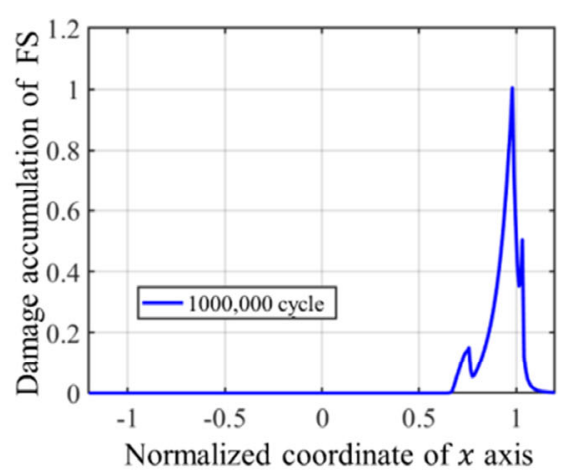

(b)

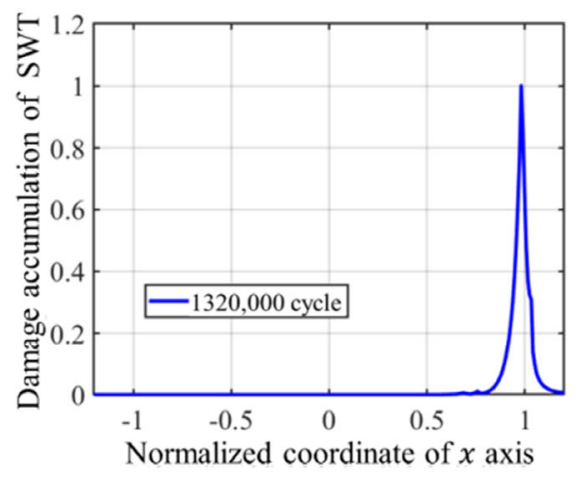

(c)

Fig. 19 Variation of the damage accumulation value for three critical plane parameters, when $\Delta h$ is $0.15 \mu \mathrm{m}$ for Experiment 1. 


\section{Conclusions and future work}

This paper analysed the effect of fretting wear debris on fretting fatigue crack initiation and the critical plane parameters. Hereafter, the conclusion can be given as follows:

1) The boundary condition influences the shear stress and wear profile when considering the wear in fretting fatigue model.

2) The normal load tends to affect the wear width and wear depth, tangential load affects the wear volume and phase difference affects the side where wear occurs.

3) As wear can affect fretting fatigue crack initiation, the predicted lifetime considering the effect of wear tends to be better than that without considering it as in Ref. [18] and all the predicted data lies in the $\pm 2 N_{i}$.

4) For both Ruiz parameters, $F_{1}$ and $F_{2}$, the maximum value tends to be near the boundary of the slip and stick zone.

5) The effect of the wear debris on the critical plane parameters are considered. It is found that the debris can make the profile of the critical plane parameters close to that in the model without considering the effect of wear, and move the location of crack initiation from boundary of stick and slip zone to the trailing edge. The kinematics of the debris also affects the maximum value of the critical plane parameters.

6) The predicted lifetime when considering the effect of wear debris tends to have the same accuracy with that without considering it. Therefore, wear affects crack initiation of fretting fatigue for Aluminum 2024-T351, mainly the location of crack initiation. The predicted lifetime without considering the effect of wear debris can be used as a reference for the loading case. However, the predicted crack initiation location without considering the effect of debris cannot be used for the fretting fatigue case.

In this paper, the effect of the wear debris is only considered after 100,000 cycle and the kinetics of the debris cannot be determined without experimental data. Therefore, in future work, the predicted lifetime of the crack initiation considering the debris kinematics should be further investigated.

\section{Acknowledgements}

The authors acknowledge the financial support of
Ministry of Education of the People's Republic of China Project 111. The authors wish to express their gratitude to Van Lang University, Vietnam for financial support for this research.

Open Access This article is licensed under a Creative Commons Attribution 4.0 International License, which permits use, sharing, adaptation, distribution and reproduction in any medium or format, as long as you give appropriate credit to the original author(s) and the source, provide a link to the Creative Commons licence, and indicate if changes were made.

The images or other third party material in this article are included in the article's Creative Commons licence, unless indicated otherwise in a credit line to the material. If material is not included in the article's Creative Commons licence and your intended use is not permitted by statutory regulation or exceeds the permitted use, you will need to obtain permission directly from the copyright holder.

To view a copy of this licence, visit http://creativecommons.org/licenses/by/4.0/.

\section{References}

[1] Hills D, Nowell D. Mechanics of Fretting Fatigue. Berlin (German): Springer Science \& Business Media, 2013.

[2] Zhang Z N, Pan S H, Yin N, Shen B, Song J. Multiscale analysis of friction behavior at fretting interfaces. Friction 9(1): 119-131 (2021)

[3] Mahmud D N F, Abdollah M F B, Masripan N A B, Tamaldin N, Amiruddin H. Influence of contact pressure and sliding speed dependence on the tribological characteristics of an activated carbon-epoxy composite derived from palm kernel under dry sliding conditions. Friction 7(3): 227-236 (2019)

[4] Rajasekaran R, Nowell D. Fretting fatigue in dovetail blade roots: Experiment and analysis. Tribol Int 39(10): 12771285 (2006)

[5] Gürer G, Gür C H. Failure analysis of fretting fatigue initiation and growth on railway axle press-fits. Eng Fail Anal 84: 151-166 (2018)

[6] Warhadpande A, Leonard B, Sadeghi F. Effects of fretting wear on rolling contact fatigue life of M50 bearing steel. Proc Inst Mech Eng Part J: J Eng Tribol 222(2): 69-80 (2008)

[7] Zhou J B, Liu J H, Ouyang H J, Cai Z B, Peng J F, Zhu $\mathrm{M} \mathrm{H}$. Anti-loosening performance of coatings on fasteners subjected to dynamic shear load. Friction 6(1): 32-46 (2018) 
[8] Berthier Y, Vincent L, Godet M. Fretting fatigue and fretting wear. Tribol Int 22(4): 235-242 (1989)

[9] Shen Y, Zhang D K, Ge S R. Effect of fretting amplitudes on fretting wear behavior of steel wires in coal mines. Min Sci Technol China 20(6): 803-808 (2010)

[10] Li J, Lu Y H. Effects of displacement amplitude on fretting wear behaviors and mechanism of Inconel 600 alloy. Wear 304(1-2): 223-230 (2013)

[11] Leonard B D, Ghosh A, Sadeghi F, Shinde S, Mittelbach M. Third body modeling in fretting using the combined finitediscrete element method. Int J Solids Struct 51(6): 13751389 (2014)

[12] Leonard B D, Patil P, Slack T S, Sadeghi F, Shinde S, Mittelbach M. Fretting wear modeling of coated and uncoated surfaces using the combined finite-discrete element method. J Tribol 133(2): 021601 (2011)

[13] McColl I R, Ding J, Leen S B. Finite element simulation and experimental validation of fretting wear. Wear 256(11-12): 1114-1127 (2004)

[14] Pereira K, Yue T, Abdel Wahab M. Multiscale analysis of the effect of roughness on fretting wear. Tribol Int 110: 222-231 (2017)

[15] Yue T Y, Abdel Wahab M. A numerical study on the effect of debris layer on fretting wear. Materials 9(7): 597 (2016)

[16] Yue T Y, Abdel Wahab M. Finite element analysis of fretting wear under variable coefficient of friction and different contact regimes. Tribol Int 107: 274-282 (2017)

[17] Bhatti N A, Pereira K, Abdel Wahab M. Effect of stress gradient and quadrant averaging on fretting fatigue crack initiation angle and life. Tribol Int 131: 212-221 (2019)

[18] Bhatti N A, Abdel Wahab M. A numerical investigation on critical plane orientation and initiation lifetimes in fretting fatigue under out of phase loading conditions. Tribol Int 115: 307-318 (2017)

[19] Bhatti N A, Abdel Wahab M. Fretting fatigue damage nucleation under out of phase loading using a continuum damage model for non-proportional loading. Tribol Int 121: 204-213 (2018)

[20] Bhatti N A, Abdel Wahab M. Fretting fatigue crack nucleation: A review. Tribol Int 121: 121-138 (2018)

[21] Pereira K, Abdel Wahab M. Fretting fatigue lifetime estimation using a cyclic cohesive zone model. Tribol Int 141: 105899 (2020)

[22] Madge J J, Leen S B, McColl I R, Shipway P H. Contactevolution based prediction of fretting fatigue life: Effect of slip amplitude. Wear 262(9-10): 1159-1170 (2007)

[23] Madge J J, Leen S B, Shipway P H. The critical role of fretting wear in the analysis of fretting fatigue. Wear 263 (1-6): 542-551 (2007)

[24] Shen F, Hu W P, Meng Q C. A damage mechanics approach to fretting fatigue life prediction with consideration of elasticplastic damage model and wear. Tribol Int 82: 176-190 (2015)

[25] Ding J, Houghton D, Williams E J, Leen S B. Simple parameters to predict effect of surface damage on fretting fatigue. Int J Fatigue 33(3): 332-342 (2011)

[26] O'Halloran S M, Shipway P H, Connaire A D, Leen S B, Harte A M. A combined wear-fatigue design methodology for fretting in the pressure armour layer of flexible marine risers. Tribol Int 108: 7-15 (2017)

[27] Madge J J, Leen S B, Shipway P H. A combined wear and crack nucleation-propagation methodology for fretting fatigue prediction. Int J Fatigue 30(9): 1509-1528 (2008)

[28] Giner E, Sukumar N, Denia F D, Fuenmayor F J. Extended finite element method for fretting fatigue crack propagation. Int J Solids Struct 45(22-23): 5675-5687 (2008)

[29] Giner E, Sukumar N, Tarancón J E, Fuenmayor F J. An Abaqus implementation of the extended finite element method. Eng Fract Mech 76(3): 347-368 (2009)

[30] Llavori I, Zabala A, Urchegui M A, Tato W, Gómez X. A coupled crack initiation and propagation numerical procedure for combined fretting wear and fretting fatigue lifetime assessment. Theor Appl Fract Mech 101: 294-305 (2019)

[31] Hattori T, Watanabe T. Fretting fatigue strength estimation considering the fretting wear process. Tribol Int 39(10): 1100-1105 (2006)

[32] Rabczuk T, Belytschko T. Cracking particles: A simplified meshfree method for arbitrary evolving cracks. Int J Numer Methods Eng 61(13): 2316-2343 (2004)

[33] Areias P, Reinoso J, Camanho P P, César de Sá J, Rabczuk T. Effective 2D and 3D crack propagation with local mesh refinement and the screened Poisson equation. Eng Fract Mech 189: 339-360 (2018)

[34] Rabczuk T, Zi G, Bordas S, Nguyen-Xuan H. A simple and robust three-dimensional cracking-particle method without enrichment. Comput Methods Appl Mech Eng 199(37-40): 2437-2455 (2010)

[35] Wang D G, Li X W, Wang X R, Zhang D K, Wang D A. Dynamic wear evolution and crack propagation behaviors of steel wires during fretting-fatigue. Tribol Int 101: 348-355 (2016)

[36] Zhang D K, Yang X H, Chen K, Zhang Z F. Fretting fatigue behavior of steel wires contact interface under different crossing angles. Wear 400-401: 52-61 (2018)

[37] Shen Y, Zhang D K, Duan J J, Wang D G. Fretting wear behaviors of steel wires under friction-increasing grease conditions. Tribol Int 44(11): 1511-1517 (2011)

[38] Ruiz C, Boddington P H B, Chen K C. An investigation of fatigue and fretting in a dovetail joint. Exp Mech 24(3): 208-217 (1984) 
[39] Bhatti N A, Wahab M A. Finite element analysis of fretting fatigue under out of phase loading conditions. Tribol Int 109: 552-562 (2017)

[40] Findley W N. A theory for the effect of mean stress on fatigue of metals under combined torsion and axial load or bending. J Eng Ind 81(4): 301-305 (1959)

[41] Szolwinski M P, Farris T N. Observation, analysis and prediction of fretting fatigue in 2024-T351 aluminum alloy. Wear 221(1): 24-36 (1998)

[42] Park J, Nelson D. Evaluation of an energy-based approach and a critical plane approach for predicting constant amplitude multiaxial fatigue life. Int J Fatigue 22(1): 23-39 (2000)

[43] Numerical Modelling of Fretting Fatigue Crack Nucleation under Out-of-Phase Loading. Ph.D. Thesis. Ghent (Belgium): Ghent University, 2018.

[44] Fatemi A, Socie D F. A critical plane approach to multiaxial fatigue damage including out-of-phase loading. Fatigue Fract Eng Mater Struct 11(3): 149-165 (1988)

[45] Neu R W, Pape J A, Swalla D R. Methodologies for linking nucleation and propagation approaches for predicting life under fretting fatigue. In Fretting fatigue: current technology and practices: ASTM International, 2000.

[46] Socie D. Critical plane approaches for multiaxial fatigue damage assessment. In Advances in multiaxial fatigue: ASTM International, 1993.

[47] Szolwinski M P, Farris T N. Mechanics of fretting fatigue crack formation. Wear 198(1-2): 93-107 (1996)

[48] Fouvry S, Duó P, Perruchaut P. A quantitative approach of Ti-6Al-4V fretting damage: Friction, wear and crack nucleation. Wear 257(9-10): 916-929 (2004)

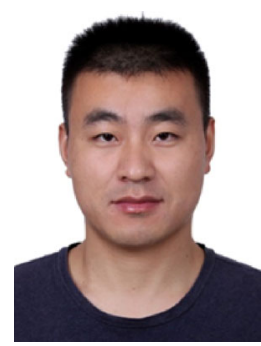

Shengjie WANG. He received his B.S. degree in mechanical design, manufacturing and automation at China University of Petroleum (East China) in 2013. He applied a Ph.D. program of Ghent University in 2017. He has been conducting

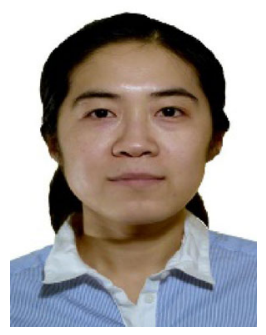

Tongyan YUE. She received her Ph.D. degree in electromechanical engineering from Ghent University, Belgium in 2016. She joined the State Grid Xinyuan Maintenance Branch
[49] Archard J F. Contact and rubbing of flat surfaces. J Appl Phys 24(8): 981-988 (1953)

[50] Miner M A. Cumulative damage in fatigue. J Appl Mech 12(3): A159-A164 (1945)

[51] Cardoso R A, Doca T, Néron D, Pommier S, Araújo J A. Wear numerical assessment for partial slip fretting fatigue conditions. Tribol Int 136: 508-523 (2019)

[52] DOD, US. Metallic Materials and elements for aerospace vehicle structures. In United States Department of Defense, Washington, DC, America, 1998.

[53] Blatt P A. Evaluation of fatigue crack initiation behavior of an experimental ternary aluminum-lithium alloy. West Lafayette (USA): Purdue University, 1990.

[54] Ashwin A, Hari Lakshman R B, Chand Swaroop C B, Vignesh M, Vaira Vignesh R, Padmanaban R. Predicting the wear rate of aluminum alloy AA2024-T351 using hybrid linear function and radial basis function. IOP Conf Ser: Mater Sci Eng 561: 012046 (2019)

[55] Wang S J, Khatir S, Abdel Wahab M. Proper Orthogonal Decomposition for the prediction of fretting wear characteristics. Tribol Int 152: 106545 (2020)

[56] Johnson K L, Johnson K L. Contact mechanics. Cambridge (UK): Cambridge university press, 1987.

[57] Kumar G B V, Rao C S P, Selvaraj N, Bhagyashekar M S. Studies on al6061-SiC and al7075- $\mathrm{Al}_{2} \mathrm{O}_{3}$ metal matrix composites. J Miner Mater Charact Eng 9(1): 43-55 (2010)

[58] Bhatti N A, Pereira K, Abdel Wahab M. A continuum damage mechanics approach for fretting fatigue under out of phase loading. Tribol Int 117: 39-51 (2018)

[59] Hirsch M R, Neu R W. A simple model for friction evolution infretting. Wear 301(1-2): 517-523 (2013)

research in the areas of finite element modeling of fretting wear and fretting fatigue at the Department of Electromechanical Systems and Metal Engineering, Ghent University, from 2017 to 2021. He has obtained his Ph.D. degree in electromechanical engineering at Ghent University.

as a metal engineer in 2017. Her work interests include non-destructive testing of metal parts, finite element and failure analysis of bolts in hydro-power unit. 


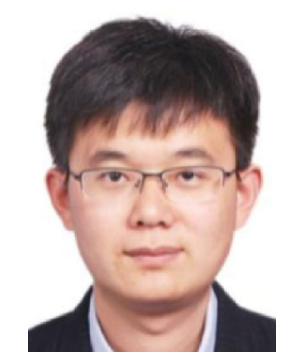

Dagang WANG. He received his B.S. and Ph.D. degrees in mechanical engineering from China University of Mining and Technology, China, in 2007 and 2012, respectively. He joined the School of Mechatronic

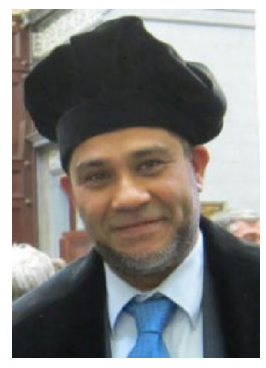

Magd ABDEL WAHAB. He is a full professor of applied mechanics in the Faculty of Engineering and Architecture at Ghent University, Belgium. He has published more than 500 scientific papers, and has
Engineering from 2013. His current position is an associate professor. His research areas cover fretting fatigue, fretting corrosion fatigue, friction transmission, tribo-fatigue, and tribo-brake.

written and edited more than 25 books and proceedings in the field of engineering. His research interests include finite element analysis, computational mechanics, fracture mechanics, damage mechanics, fretting fatigue, and fretting wear. 